\title{
THE DECEMBER MEETING IN PASADENA
}

The three hundred sixty-fourth meeting of the Society was held at the California Institute of Technology, Pasadena, California, on Saturday, December 2, 1939. The attendance was about seventy-five including the following forty-seven members of the Society:

C. R. Adams, R. B. Adams, O. W. Albert, L. D. Ames, H. M. Bacon, Harry Bateman, Clifford Bell, H. F. Blichfeldt, H. F. Bohnenblust, C. P. Brady, J. L. Brenner, F. A. Butter, W. D. Cairns, A. B. Coble, P. H. Daus, A. L. Foster, W. H. Gage, H. E. Glazier, H. J. Hamilton, W. L. Hart, E. R. Hedrick, P. G. Hoel, D. G. Humm, C. G. Jaeger, G. F. McEwen, Rhoda Manning, W. A. Manning, A. D. Michal, C. B. Morrey, W. T. Puckett, E. J. Purcell, T. M. Putnam, R. W. Rector, A. C. Schaeffer, G. E. F. Sherwood, Gabor Szegö, A. E. Taylor, B. P. Taylor, S. E. Urner, F. A. Valentine, Morgan Ward, L. E. Wear, D. E. Whelan, M. B. White, W. M. Whyburn, E. R. Worthington, Max Zorn.

A general session was held Saturday morning and another in the afternoon. Professors Michal, Adams, Coble and Szegö presided at various times. At the morning session Professor C. B. Morrey of the University of California gave an address on Existence and differentiability theorems for the solutions of variational problems for multiple integrals. At the close of the afternoon session Professor and Mrs. Michal entertained at tea for members of the Society and their friends.

The titles and cross references to abstracts of papers read at the meeting are given below. Papers whose abstract numbers are followed by the letter $t$ were read by title. Mr. Max Wyman, Mr. A. B. Mewborn and Mr. J. P. LaSalle were introduced by Professor Michal.

1. Rhoda Manning: On the derivatives of the sections of bounded power series. (Abstract 46-1-22.)

2. E. J. Purcell: A multiple null-correspondence and a space Cremona involution of order 2n-1. (Abstract 46-1-29.)

3. P. G. Hoel: The errors involved in evaluating correlation determinants. (Abstract 46-1-18.)

4. C. R. Adams and A. P. Morse: Continuous additive functionals on the space (BV) and certain subspaces. (Abstract 46-1-1.)

5. Max Wyman: Curl differential equations in abstract spaces. (Abstract 46-1-40.)

6. A. L. Foster: The structure of regularly ordered natural systems with 3 primes. (Abstract 46-1-14.)

7. H. F. Bohnenblust: Axiomatic characterization of $l_{p}$ spaces. (Abstract 46-1-11.)

8. A. B. Mewborn: Abstract local geometry of paths. Preliminary report. (Abstract 46-1-24.) 
9. J. P. LaSalle: Linear functions and functionals in linear topological spaces. Preliminary report. (Abstract 46-1-21.)

10. Max Zorn: Topological studies in the theory of analytic functions. II. Potential functions. Preliminary report. (Abstract 46-1-42). 38).

11. Morgan Ward: Residuated distributive lattices. (Abstract 46-1-

12. A. C. Schaeffer and Gabor Szegö: Polynomials whose real part is bounded on a Jordan curve in the complex plane. (Abstract 46-1-118.)

13. E. P. Vance: On locally non-separating and locally non-alternating transformations. (Abstract 46-1-37-t).

14. W. F. Whitmore: Convergence theorems for functions of two complex variables. (Abstract 46-1-39-t.)

15. A. D. Michal: Differentials in abstract abelian topological groups. (Abstract 46-1-25-t.)

16. Max Wyman: Projective non-holonomic tensor analysis. (Abstract 46-1-41-t.)

17. E. T. Bell: Transformed multiplicative diophantine equations. (Abstract 46-1-7-t.)

18. R. M. Robinson: On the mean values of an analytic function. (Abstract 46-1-116-t.)

T. M. Putnam, Associate Secretary 